\title{
Design and placement of synthetic sex pheromone traps for cacao mirids in Ghana
}

\author{
J.E. Sarfo ${ }^{1}$, C.A.M. Campbell ${ }^{2 *}$ and D.R. Hall ${ }^{2}$ \\ ${ }^{1}$ Cocoa Research Institute of Ghana, PO Box 8, New Tafo, Ghana; ${ }^{2}$ Natural \\ Resources Institute, University of Greenwich, Chatham Maritime, Kent, \\ ME4 4TB, UK
}

\begin{abstract}
Cacao mirids (Sahlbergella singularis, Distantiella theobroma and Bryocoropsis laticollis) were captured in pheromone traps releasing a 2:1 blend of the sex pheromone components of the two first $\mathrm{n}$ amed s pecies in a $\mathrm{s}$ eries of fi ve ex periments on cacao (Theobroma cacao) plantations in Ghana. A total of 835 cacao mirids were caught, all male, $95 \%$ of which were $S$. singularis, $3 \% D$. theobroma and $2 \%$ B. laticollis. Two sticky trap and two water trap designs made from locally available materials were as effective for capturing $S$. singularis and total mirids as the best sticky trap from previously reported studies. Coating the outer surface of a large water trap with sticker increased the catch $4.4 \times$, and $2.7 \times$ for a cylindrical sticky trap. Sticker on the outside of the water trap also increased the inside catch of $S$. singularis by $76 \%$ and total mirids by $71 \%$. The numbers of $S$. singularis and $D$. theobroma trapped increased with increasing trap elevation and were highest around canopy level. Those traps caught an average $12 \times$ more mirids than traps at $1.8 \mathrm{~m}$, the height recommended currently. Therefore, large water traps coated with sticker and aligned with the cacao canopy should raise the current capture rates of pheromone traps for cacao mirids about $50 \times$, which may be sufficient for effective pest management by mass trapping without synthetic insecticides.
\end{abstract}

Key words: Mirid, Theobroma cacao, pheromone trap, Sahlbergella singularis, Distantiella theobroma, Bryocoropsis laticollis

\section{Introduction}

Cocoa is a valuable export crop for several West African countries (including Ghana), where it is the largest agricultural commodity. It accounted for $16.4 \%$ of its export receipts in 2013 (SGER, 2013). In West Africa, the most damaging pests of cacao are the mirids, Sahlbergella singularis Haglund and Distantiella theobroma Distant (all Hemiptera: Miridae) (Entwistle, 1972; Collingwood, 1977). The former attacks cacao from Sierra Leone to Central African Republic, almost twice the geographical range of $D$. theobroma whose centre of abundance is Ghana, where it was once the more damaging of the two species (Collingwood, 1977). In Ghana, mirids cause losses estimated at $25-30 \%$ per annum

*E-mail: Distantiella@yahoo.co.uk and as high as $75 \%$ in poorly managed farms (Stapley and Hammond, 1959; Johnson, 1962). Babin et al. (2004) and Anikwe and Makanjuola (2013) have reported similar losses from elsewhere in West Africa. Damage varies from mild 'blast' (where leaves on fan branches die but remain hanging), to 'staghead' (where the whole canopy of individual trees is defoliated and shoots die back), to the most severe 'pockets' (where up to 100 trees become stagheaded, with corresponding breaks in the cacao canopy) (Johnson, 1962). For decades, the main method of mirid control has been foliar application of chemical insecticides (Johnson, 1962; Collingwood and Marchart, 1971; Owusu-Manu, 2002). However, an increasing market demand for organically produced cacao (Mahrizal et al., 2012), problems with pesticide-induced secondary pest outbreaks (Entwistle et al., 1959), and a desire to 
minimize pesticide usage has stimulated research for more ecologically benign methods of control (Babin et al., 2004; Anikwe and Makanjuola, 2013), including sex pheromones (Padi et al., 2002; Ayenor et al., 2007; Mahob et al., 2011).

Pheromone traps have become important tools for monitoring and managing pest populations in a range of crops (Witzgall et al., 2010). Female $S$. singularis and D. theobroma were found to produce the same two pheromone components in essentially the same ratio (Downham et al., 2002; Padi et al., 2002). Thomson et al. (1999) report that varying pheromone trap design and placement can produce big differences in the numbers of insects trapped. In Cameroon, Mahob et al. (2011) showed that a rectangular trap constructed from fluted PVC sheet caught almost three times more male $S$. singularis than did a commercial delta trap, a finding that confirmed findings from an earlier experiment in Ghana using the same trap designs, in which four times more mirids were caught in the rectangular traps than in delta traps (Padi et al., 2002). Both trap types consisted of imported materials. While the costs of such imports may be affordable for research studies, if pheromone trapping was expanded country- or region-wide (either for monitoring or for mass trapping) (Ayenor et al., 2007), locally sourced options would be preferable, to reduce costs and unnecessary imports, and to ensure continuity of supply.

Mahob et al. (2011) deployed their pheromone traps at about $2 \mathrm{~m}$ above ground, near to the height found most effective by Sarfo et al. (2007), using the same design of rectangular trap. Sarfo et al. (2007) used caged virgin female S. singularis as trap bait and found that $3.5 \mathrm{x}$ more males were trapped at $1.8 \mathrm{~m}$ than at $2.7 \mathrm{~m}$, and almost twice that at $0.6 \mathrm{~m}$. However, these findings were made in a relatively small experiment using six traps at each height and at a single location, so would benefit from confirmation at a wider range of sites and at a more extensive range of heights. In addition, trap height recommendations using virgin females as bait may not be optimal for traps using a synthetic lure, as observed by Yonce et al. (1976) in the case of the lesser peachtree borer, Synanthedon pictipes (Grote \& Robinson) (Lepidoptera: Sessiidae).

The objectives of the present study were to: (a) design a pheromone trap for cacao mirids from locally available materials that are at least as effective as the current best trap; and (b) determine the optimal placement of traps to maximize the catch.

\section{Materials and methods}

\section{Study sites and experimental plots}

Five experiments were made. Three were made on farmers' cacao at Suhyen $\left(6^{\circ} 10^{\prime} \mathrm{N}, 0^{\circ} 19^{\prime} \mathrm{W}\right)$ and
Akwadum (two sites, $5^{\circ} 59^{\prime} \mathrm{N}, 0^{\circ} 44^{\prime} \mathrm{W}$ ), and one each on CRIG research plantations at Acherensua $\left(7^{\circ} 1^{\prime} \mathrm{N}\right.$, $\left.2^{\circ} 16^{\prime} \mathrm{W}\right)$ and Afosu $\left(6^{\circ} 23^{\prime} \mathrm{N}, 1^{\circ} 0^{\prime} \mathrm{W}\right)$. Cacao trees at farmers' sites were spaced irregularly, whereas those at CRIG sites were spaced $3 \mathrm{~m} \times 3 \mathrm{~m}$ on a square planting. The cacao trees at all sites were upper amazon hybrids growing under partial shade from forest trees, with mostly closed canopies. Occasional canopy breaks were often the sites of mirid pockets, and wherever feasible, they were incorporated as plots for the experiments. No insecticides were applied for at least three months before experiments were started and during the trapping periods. Trees were about 10 years old and 3.5-6.5 $\mathrm{m}$ tall in the 7 ha and 3 ha sites at Akwadum, about 15 years old at the 1.5 ha site at Suhyen, 25 years at the 3.5 ha site at Acherensua and 30 years at Afosu in a 10 ha site. At the latter three sites, tree height varied between about $6.0-6.5 \mathrm{~m}$ high.

The mirid pheromone was dispensed from polyethylene vials $(20 \times 8$ dia. $\times 1.5 \mathrm{~mm}$ thick; Just Plastics Ltd., Norwich, UK) charged with $1.5 \mathrm{mg}$ of a 2:1 ratio of the diester, hexyl $(R)-3-$ ((E)-2-butenoy1)-butyrate, and the corresponding monoester, hexyl (R)-3-hydroxybutyrate and 1.5 mg 4-methyl-2,6-di-tert-butylphenol as antioxidant. The pheromone components were prepared at the Natural Resources Institute and were $>95 \%$ pure by gas chromatographic analysis. Single lures, suspended 1-2 $\mathrm{cm}$ above the lowest heights of the apertures, were replaced at least monthly. The traps were either cleaned or replaced at the same intervals. A polybutene sticker (Agralan, Ashton Keynes, Wilts., UK) was used for sticky traps and a dilute solution of detergent in water in bottle traps.

\section{Experiment 1: trap design}

Five trap designs (three sticky and two water) were compared in the 7 ha site at Akwadum, using a randomized complete block design (RCBD) replicated eightfold. The aperture of all traps was standardized at $280 \mathrm{~cm}^{2}$ and in each trap a single lure was suspended by a wire $c a 2 \mathrm{~cm}$ above the trapping medium. The traps (Fig. 1A-E) were as follows: (1) the rectangular design, as used by Sarfo et al. (2007) and Mahob et al. (2011) constructed from fluted PVC sheet ('Correx'; Sign Trade Supplies, Maidstone, $\mathrm{UK})$, folded into open-ended boxes $38 \mathrm{~L} \times 10 \mathrm{~W} \times$ $14 \mathrm{H} \mathrm{cm}$ lined with a second Correx sheet $38 \mathrm{~L} \times 9.6 \mathrm{~W}$ $\times 12 \mathrm{H} \mathrm{cm}$ coated with sticker on sides and base, and deployed horizontally; (2) two circular plastic soup dishes from the local market deployed face down with the upper dish $(18 \mathrm{~cm}$ dia.) separated from the lower ( $16 \mathrm{~cm}$ dia.) by a $5 \mathrm{~cm}$ wooden pillar. The upper surface of the lower dish was coated with sticker; (3) a cylinder trap constructed from 

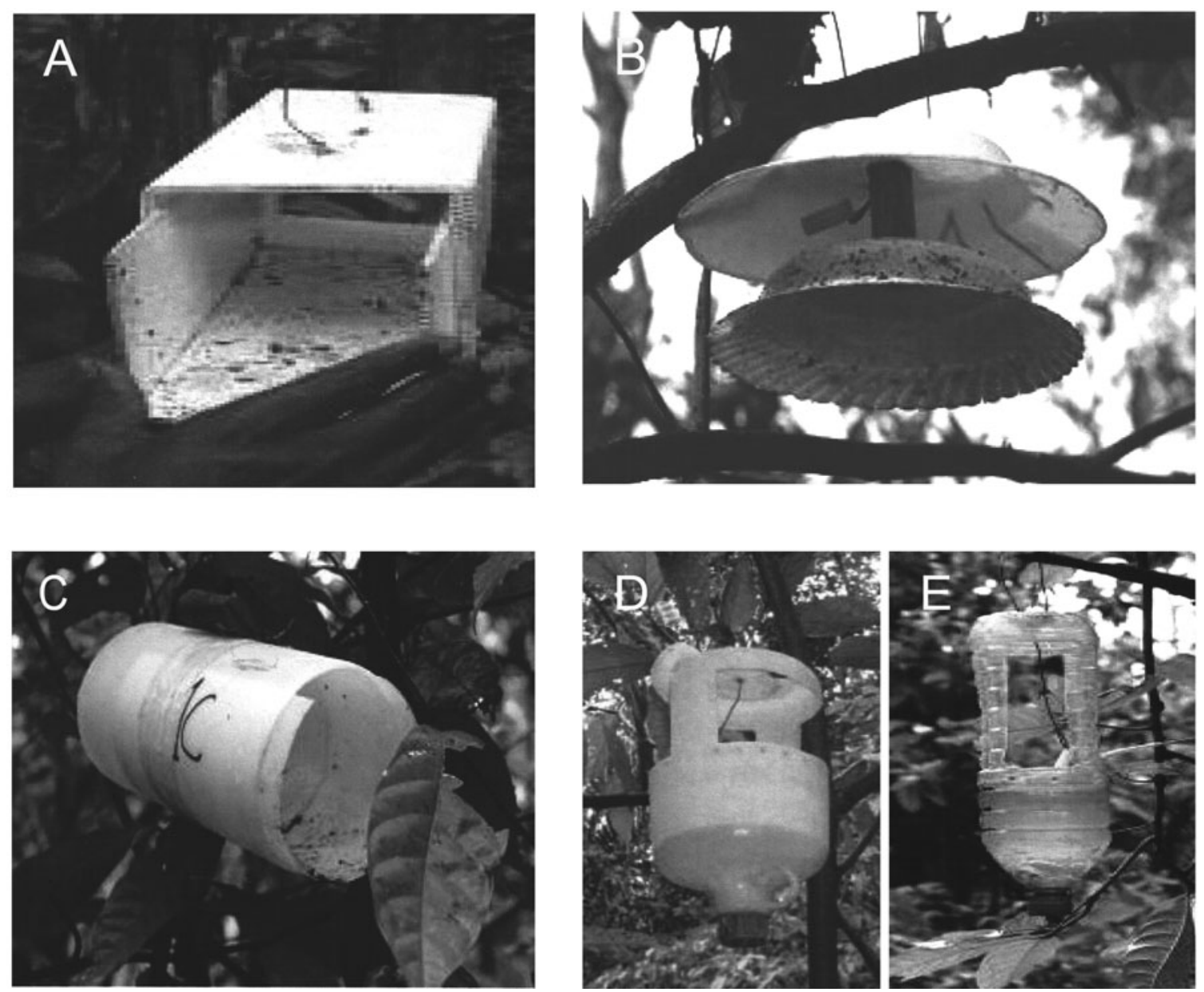

Fig. 1. Pheromone traps tested. A: Rectangular (sticky tray part exposed for illustration), B: Dish (entire upper surface of lower dish with sticker), C: Cylinder (sticky liner part exposed for illustration), D: Large bottle and E: Small bottle. In operation, bottle traps are filled to $1 \mathrm{~cm}$ below the aperture with water. A pheromone lure suspended by wire is visible in traps A, B, D and E, but obscured in C by the angle of view. The aperture of all traps is a standardized $280 \mathrm{~cm}^{2}$.

two 2.5L high-density polyethylene (HDPE) bottles $(13.4 \mathrm{~cm}$ dia.) with the neck portions removed and joined to form a hollow cylinder $34 \mathrm{~L} \mathrm{~cm}$ and with an insert of the same material cut to occupy about $80 \%$ of the inner surface and coated with sticker. The cylinder was deployed horizontally; (4) large water trap constructed from a $4.5 \mathrm{~L}$ polyurethane bottle $(26 \mathrm{H} \times 16 \mathrm{~cm}$ dia.) with two opposed windows (each $7.0 \times 20 \mathrm{~cm}$ ) cut in the sides; (5) small water trap constructed from a $1.5 \mathrm{~L}$ polyethylene terephthalate (PET) water bottle $(31.0 \mathrm{H} \times 8.0 \mathrm{~cm}$ dia.) with four windows $(5 \times 14 \mathrm{~cm})$ spaced equidistant radially. The bottle traps were inverted and filled to just below window level with the trapping solution. The traps were suspended from cacao trees at a height of $1.8 \mathrm{~m}$, with an inter-trap spacing of $20 \mathrm{~m}$ and interblock spacing of $40 \mathrm{~m}$. Traps were emptied three times a week and systematically moved to the next position in each block at fortnightly intervals, so that each type of trap was exposed for the same length of time in every position in each plot. As Perry et al. (1980) pointed out, such a systematic rotation of traps forms a Latin square design. The experiment was run from 3 March 2007-30 May 2008, and was halted after six rotations of the treatments when it was apparent that the null hypothesis of no significant difference between treatments would not be rejected.

\section{Experiment 2: increased trapping surface area}

Behavioural observations, made while conducting Experiment 1, showed that male mirids often landed first on the outer surface of traps from whence they either entered and became trapped, or dispersed and escaped immediate capture. This experiment at Afosu aimed to assess whether trap efficiency could be improved by increasing the 
retention area. Mirid pockets of at least $30 \times 30 \mathrm{~m}$ and at least $40 \mathrm{~m}$ apart were chosen for the experiment. A RCBD was used, replicated eightfold. The four traps in each block were arrayed 20 $\mathrm{m}$ apart in a square pattern. The treatments were: (1) the large water trap as described above, (2) large water trap with the outer surface completely coated with sticker, (3) sticky cylinder trap as described above, and (4) cylinder trap with the outer surface coated with sticker. Traps were emptied weekly and their positions moved round so that every trap in each block was exposed for an equal time in each quarter. Unlike Experiment 1, and in light of new evidence, the traps were deployed immediately below cacao canopy height. The experiment was run from 10 May-14 June 2011 and was halted after one full rotation of treatments, as $F$-tests already showed $(P<0.001)$ that the objectives were met.

The following three experiments were made with the aim of establishing the optimal height(s) and pattern of deployment of traps. The large bottle traps described in Experiment 1 were used.

\section{Experiment 3: effect of traps at three heights on the same cacao tree}

The experiment was made at Acherensua. Traps were suspended at $0.6,1.8$ and $2.7 \mathrm{~m}$ above ground level on a single cacao tree at 15 locations spaced at least $20 \mathrm{~m}$ apart. The 45 traps were emptied fortnightly and the experiment run from 28 January20 July 2009, and halted once F-tests showed $(P<0.001)$ that the objectives were met.

\section{Experiment 4: effect of traps at different heights on single poles}

Results from Experiment 3 suggested that deploying traps at elevations above $2.7 \mathrm{~m}$ might be beneficial. The experiment was made at Suhyen from 12 March-3 August 2010. Four traps were suspended from each of 10 vertical bamboo poles sited among the cacao trees at $1.8 \mathrm{~m}$ and $2.7 \mathrm{~m}$ above ground level, $0.3 \mathrm{~m}$ below the $6.5 \mathrm{~m}$ high canopy and $0.3 \mathrm{~m}$ above it. The poles were sited at least 20 $\mathrm{m}$ apart, and catches recorded weekly. The experiment was terminated after 21 weeks of trapping, once $F$-tests showed $(P<0.001)$ that the objectives were met.

\section{Experiment 5: isolated single traps}

The third height experiment was designed to test whether traps should be positioned relative to the local elevation of the tree canopy rather than at specific heights. The experiment was made in a 3 ha farm at Akwadum from 20 March-8 August 2010. Five treatments were compared in a
RCBD experiment replicated sixfold. The traps were suspended on separate trees at $1.8 \mathrm{~m}$ above ground, $2.7 \mathrm{~m}$ above ground, $0.3 \mathrm{~m}$ below the ca. $6.5 \mathrm{~m}$ high canopy, $0.3 \mathrm{~m}$ above the ca. $6.5 \mathrm{~m}$ high canopy and at $1.8 \mathrm{~m}$ and below the canopy of a $3.5 \mathrm{~m}$ high cacao tree. Short trees were relatively uncommon and were surrounded by taller trees, so it was unfeasible to deploy a trap above the canopy of the short trees, as the canopies of adjacent taller trees would shroud them. Traps were spaced at least $30 \mathrm{~m}$ apart with an inter-block spacing of at least $40 \mathrm{~m}$. Trap catches were recorded weekly. The experiment was halted after 26 weeks trapping, after successive $F$-tests showed consistently significant differences $(P<0.05)$ between means.

\section{Data analysis}

Data were analysed using GenStat 9. Total trap catches were compared by ANOVA either raw, or transformed $(\sqrt{ } \mathrm{x}+0.5)$ to stabilize error variances. However, we found that the transformation neither altered the relationships between variables nor altered the statistical significance of the $F$-values and the significances of differences between means. Nonetheless, all ANOVA's were performed on transformed data, to preserve the validity of the distributional assumptions, but all means and SEs are presented using untransformed data, as this aids interpretation.

Two trap heights $(1.8$ and $2.7 \mathrm{~m})$ were common treatments in the three height experiments. Pimentel-Gomes' (1970) method for jointly analysing RCBD experiments with common treatments was used to combine the three height experiments in a single ANOVA, to improve the precision of the estimated optimal trap height.

A perusal of the data from Experiment 2 suggested that applying a sticker to the outside of the traps increased the overall catch and numbers of mirids entering traps coated with additional sticker. We examined this possibility by partitioning the variance and applying a linear contrast of numbers caught inside sticker-coated traps vs. numbers caught inside non-coated traps. Where ANOVA indicated significant $F$-ratios $(P<0.05)$, differences between means were compared by Student-Newman-Keuls (SNK) test.

\section{Results}

Sahlbergella singularis dominated the catches in all experiments (Table 1 ), followed by $D$. theobroma, which was trapped at four of the five sites, but in low numbers, and by $B$. laticollis, which was trapped at two sites (Akwadum and Afosu). Males only were trapped. 
Table 1. Total numbers captured in sex-pheromone traps of male Sahlbergella singularis, Distantiella theobroma and Bryocoropsis laticollis (Heteroptera: Miridae)

\begin{tabular}{lcccrr}
\hline Experiment no. (trapping period) & No. of traps & S. singularis & D. theobroma & B. laticollis & Total \\
\hline $1(3 / 3 / 2007-30 / 5 / 2008)$ & 40 & 308 & 0 & 1 & 309 \\
$2(10 / 5 / 2011-14 / 6 / 2011)$ & 32 & 135 & 1 & 15 & 151 \\
$3(28 / 1 / 2009-20 / 7 / 2009)$ & 45 & 97 & 5 & 0 & 102 \\
$4(12 / 3 / 2010-3 / 8 / 2010)$ & 40 & 148 & 9 & 0 & 157 \\
$5(20 / 2 / 2010-8 / 8 / 2010)$ & 30 & 108 & 8 & 0 & 116 \\
Total catch & & 796 & 23 & 16 & 835 \\
\hline
\end{tabular}

Table 2. Mean $( \pm \mathrm{SE})$ catch of male cacao mirids in eight replicates of each trap treatment (Afosu; 10 May-14 June 2011)

\begin{tabular}{|c|c|c|c|c|}
\hline \multirow[b]{2}{*}{ Trap } & \multicolumn{2}{|c|}{ Mean $^{+}( \pm S E)$ catch } & \multicolumn{2}{|c|}{ Mean $( \pm S E)$ catch inside trap } \\
\hline & Sahlbergella singularis & All mirids & Sahlbergella singularis & All mirids \\
\hline Bottle & $2.1 c(0.48)$ & $2.3 c(0.45)$ & $2.1 \mathrm{a}(0.48)$ & $2.3 \mathrm{a}(0.45)$ \\
\hline Bottle + sticker & $9.4 a(1.83)$ & 10.1a (1.83) & $3.6 a(0.84)$ & $3.8 \mathrm{a}(0.77)$ \\
\hline Cylinder & $1.5 c(0.50)$ & $1.6 \mathrm{c}(0.60)$ & $1.5 \mathrm{a}(0.50)$ & $1.6 \mathrm{a}(0.60)$ \\
\hline Cylinder + sticker & $4.0 \mathrm{~b}(0.96)$ & $4.9 \mathrm{~b}(1.14)$ & $2.8 \mathrm{a}(0.73)$ & $2.9 \mathrm{a}(0.79)$ \\
\hline
\end{tabular}

${ }^{+}$Means in the same column followed by the same letter are non-significantly different $P>0.05$ by SNK test.

\section{Experiment 1: trap design}

No significant differences between any of the trap designs in the numbers of $S$. singularis caught $(F=0.10, \mathrm{df}=4,28, P>0.05)$ with mean $( \pm \mathrm{SE})$ totals of $5.6( \pm 1.16), 7.7( \pm 3.10), 6.6( \pm 0.86), 8.3( \pm 4.79)$ and 7.5 mirids $( \pm 3.14)$ in rectangular, dish, cylinder, large and small water bottle traps, respectively, were noted. Although no significant differences between treatments were recorded, the large bottle traps were selected for the height experiments, as they had the highest mean catches and were constructed from local materials.

\section{Experiment 2: increased trapping surface area}

Increasing the trap catch area with an external coating of sticker increased the total catch of $S$. sing $u$ laris by 4.4-fold for large bottle traps and 2.7-fold for cylindrical traps $(F=5.99 ; \mathrm{df}=5,35, P<0.001)$ (Table 2), suggesting that $80 \%$ of $S$. singularis males that responded to the pheromone released from bottle traps dispersed and avoided capture. Similarly, adding data for the other two mirid pests increased the difference marginally for bottle traps to 4.5 -fold, and to 3.0-fold for the cylinder trap $(F=6.73 ; \mathrm{df}=5.35, P<0.001)$. The one $D$. theobroma caught (Table 1) was trapped in sticker on the outer surface of a trap, as were 11 of the $15 \mathrm{~B}$. laticollis caught, but the difference between numbers caught inside and outside of traps for the latter species was non-significant $\left(\chi^{2}=2.4\right.$ with Yates' correction).

Spreading sticker on the outside of traps also increased significantly the overall numbers of
S. singularis caught inside those traps compared to unenhanced traps (Mean $( \pm$ SE) enhanced $=3.2$ $( \pm 0.55)$, unenhanced $=1.8( \pm 0.34) ; F=4.5 ; \mathrm{df}=1,35$, $P<0.05)$ and similarly for total mirids (enhanced $=$ $3.3( \pm 0.55)$, unenhanced $=1.9( \pm 0.37) ; F=5.60 ; \mathrm{df}$ $=1,35, P<0.05)$, but failed to increase the catches in the two trap types individually (Table 2).

The results from this experiment further confirm the parity of performance between unenhanced bottle and cylinder traps found in Experiment 1, as there were no significant differences in mean catches between these two trap types (Table 2).

\section{Experiment 3: effect of traps at three heights on the same cacao tree}

The mean catch of $S$. singularis increased exponentially with increasing trap height (Fig. 2). The best-fit exponential curve (SE of parameter in parentheses) was $y=0.27( \pm 1.23)+0.117( \pm 0.397) \times$ $3.74( \pm 4.37)^{\mathrm{x}}$, which explained $26.6 \%$ of the variance and $52.8 \%$ after the inclusion of separate parameters for each block. The equation for the exponential curve using transformed data provided a marginally better fit (31.1 and $56.2 \%$ of variance explained, respectively). The catch was significantly greater at $2.7 \mathrm{~m}(F=10.93 ; \mathrm{df}=2,42 ; P<0.001)$ than at 0.6 and $1.8 \mathrm{~m}$, which were not significantly different (Fig. 2).

\section{Experiment 4: effect of traps at different heights on single poles}

Mean catches of $S$. singularis increased significantly the closer traps approached the canopy from 


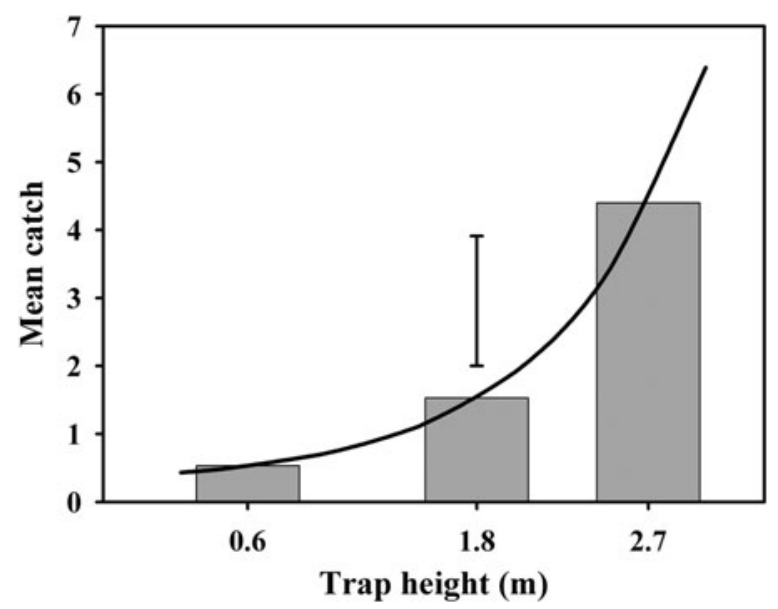

Fig. 2. Mean catch in pheromone traps of Sahlbergella singularis at three heights above ground level on a single tree (vertical line $=5 \%$ LSD), and the best fit exponential curve, $y=0.27+0.117 * 3.74^{\mathrm{x}}$ (Acherensua; 28 January-20 July 2009).

below and were significantly higher still $(P<0.05)$ just above the canopy than just below ( $F=33.98$; $\mathrm{df}=3,27, P<0.001$ ) (Table 3). Distantiella theobroma was only trapped at the two highest elevations. Six individuals were caught just below the canopy and three above it. Including them in the analysis reinforced the conclusion that traps at near canopy height were the most effective for trapping male mirids $(F=35.48, \mathrm{df}=3,27, P<0.001)$.

\section{Experiment 5: isolated single traps}

As in the previous experiment, the number of $S$. singularis caught increased with increasing trap height towards the underside of the canopy, although in this experiment no significant difference was noted between mean catch immediately below the canopy and just above it $(F=3.52$; $\mathrm{df}=4.20$, $P<0.05$ ) (Table 3 ). Significantly, more $S$. singularis were caught in traps at 2.7, 6.2 and $6.8 \mathrm{~m}$ than at $1.8 \mathrm{~m}$, whereas no significant differences between the catch at $2.7 \mathrm{~m}$ and at $1.8 \mathrm{~m}$ under low canopy trees, and no significant difference in catches at 1.8 $\mathrm{m}$ between tall and short trees (Table 3 ) were noted. Again, D. theobroma was only caught in traps at the two highest elevations with four individuals trapped at each of the locations immediately below and above the tall tree canopy $(F=3.78$; $\mathrm{df}=4,20$, $P<0.05)$, but the statistical relationships between trap positions were unaltered when these insects were included in the ANOVA.

Applying Pimentel-Gomes' (1970) method to $S$. singularis data sets from experiments $3-5$ gave adjusted means $( \pm \mathrm{SE})$ of $0.13( \pm 0.19), 0.96( \pm 0.31)$, $2.75( \pm 0.59), 6.45( \pm 0.62)$ and $6.87( \pm 0.63)$ insects at
$0.6,1.8,2.7,6.2$ and $6.8 \mathrm{~m}$, respectively, which gives an estimated optimal trap height for capture of $S$. singularis as $5.6 \mathrm{~m}( \pm 2.40 \mathrm{SD})$, on the assumption that the mean canopy height was $6.5 \mathrm{~m}$. The adjusted mean catch for the traps at $1.8 \mathrm{~m}$ under $3.5 \mathrm{~m}$ high trees was $1.79( \pm 0.19)$ insects, but was not used for calculating the optimal trap height relative to the main canopy trees. A similar analysis was impossible for $D$. theobroma, as none was trapped at 1.8 and $2.7 \mathrm{~m}$ in Experiments 4 and 5.

\section{Discussion}

Three mirid pests of cacao were trapped in the present study, 95\% S. singularis, 3\% D. theobroma and $2 \% B$. laticollis. The serendipitous capture of $B$. laticollis males in the pheromone traps suggests that, like the two more common mirid pests, it too may utilize similar sex pheromone chemistry. Collingwood (1977) reported that at that time $D$. theobroma was the most damaging of the two common mirid species averaging from 30 to $70 \%$ or more of all cacao mirid collections, although as a pest its range from Cameroon to Ivory Coast was much more restricted than that of $S$. singularis. For example, in Cameroon, its abundance was estimated as $1 \%$ of collections and from $2-18 \%$ in Nigeria, with $S$. singularis almost alone in making up the rest (Collingwood, 1977). In Cote d'Ivoire, Lavabre et al. (1963) reported that of 57,958 mirids collected over 2 years $74.2 \%$ were $S$. singularis, $25.8 \%$ $D$. theobroma and $0.01 \%$ B. laticollis. However, D. theobroma fluctuated between 0 and $93 \%$ of the mirid population at different localities in that study. Our results from five widespread sites suggest that $D$. theobroma may be declining in abundance in Ghana, as suggested by Owusu-Manu (1994). However, the low trap catches may have been due to other factors, such as the known extremely patchy distribution of this species (Collingwood, 1977), lower effectiveness of the traps and/or lures for this species and/or the trapping periods may have been outside the species outbreak period. More widespread surveys are required using pheromone traps and other means of population assessment.

The objective of the trap design experiment was to identify the best performing trap, preferably one that could be fabricated using locally available materials only. The latter consideration is important, given the large numbers of traps that would be needed in, for example, a nationwide monitoring programme, or for control by mass trapping. All of the traps tested were as effective as the rectangular design, which previous experiments had shown was superior to delta traps (Padi et al., 2002; Mahob et al., 2011). Because the local designs was as effective as the rectangular trap, factors such as cost, durability, availability of materials, ease of fabrication and 
Table 3. Mean ( \pm SE) catch of cacao mirids in traps at different heights

\begin{tabular}{|c|c|c|}
\hline \multirow[b]{2}{*}{ Trap height } & \multicolumn{2}{|c|}{ Mean $^{+}( \pm S E)$ catch } \\
\hline & Sahlbergella singularis & All mirids \\
\hline \multicolumn{3}{|c|}{ Experiment 4: traps on 15 single poles (Suhyen; 12 March-3 August 2010) } \\
\hline $1.8 \mathrm{~m}$ above ground & $0.6 \mathrm{a}(0.15)$ & $0.6 \mathrm{a}(0.15)$ \\
\hline $2.7 \mathrm{~m}$ above ground & $1.5 \mathrm{a}(0.21)$ & $1.5 \mathrm{a}(0.21)$ \\
\hline $0.3 \mathrm{~m}$ below canopy & $5.1 b(0.60)$ & $5.7 \mathrm{~b}(0.67)$ \\
\hline $0.3 \mathrm{~m}$ above canopy & $7.6 c(0.48)$ & $7.9 \mathrm{c}(0.48)$ \\
\hline \multicolumn{3}{|c|}{ Experiment 5: six replicates of isolated single traps (Akwadum; 20 March-8 August 2010) } \\
\hline $1.8 \mathrm{~m}$ above ground & $0.7 \mathrm{a}(0.34)$ & $0.7 \mathrm{a}(0.34)$ \\
\hline $2.7 \mathrm{~m}$ above ground & $3.8 \mathrm{~b}(0.43)$ & $3.8 \mathrm{~b}(0.43)$ \\
\hline $0.3 \mathrm{~m}$ below ca $6.5 \mathrm{~m}$ high canopy & $6.7 \mathrm{~b}(1.28)$ & $7.3 b(1.34)$ \\
\hline $0.3 \mathrm{~m}$ above $c a 6.5 \mathrm{~m}$ high canopy & $4.7 \mathrm{~b}(1.35)$ & $5.3 b(1.96)$ \\
\hline $1.8 \mathrm{~m}$ (canopy height $c a 3.5 \mathrm{~m})$ & $2.2 \mathrm{ab}(0.33)$ & $2.2 \mathrm{ab}(0.33)$ \\
\hline
\end{tabular}

convenience become important considerations. As the polybutene sticker used in the sticky traps must be imported, it follows that one of the water traps would be preferred for any extensive programme involving pheromone trapping.

The water traps were made from local materials that are easily available and cheap in local markets or wholesale suppliers. They were simple to fabricate and the large bottle trap was particularly durable. However, insects caught in water decompose rapidly in tropical temperatures, making identification and counting difficult (if they were left beyond a month in water traps), although replacing the water with brine may reduce decomposition. Also, the traps needed frequent topping up, owing to evaporation and/or drinking by birds and arboreal mammals. The water traps are, therefore, most suitable where no specific identification or count of the numbers of insects caught is needed (such as in a mass trapping or lureand-kill programmes).

The sticky traps were also simple to fabricate and the materials were cheap to buy. Catches by these traps were identifiable after a month; therefore, unless a local substitute sticker can be identified, such traps would be most suitable for scientific monitoring of insect numbers, where species counts are needed. Furthermore, their cost is less restricting. Although water traps have been deployed for other mirid species (e.g. Yasuda and Higuchi, 2012), this is the first study in which pheromone-baited water traps have been tested for capture of cacao mirids.

Results of the increased surface area for trapping experiment showed an up to 4.5-fold increase in catches when the outer surface was coated with sticker. This experiment suggests that perhaps $80 \%$ of mirids responding positively to the pheromone from unenhanced traps may disperse and escape capture, and if this behaviour proves species- specific, it implies that sticker-enhanced traps would be essential for monitoring species' relative abundance. Applying polybutene sticker to the exterior of water traps defeats the criterion for using only local materials. Moreover, owing to the accumulation of dust and other debris, the exposed sticky surface needs regular cleaning and replenishment. However, for non-research purposes where insect counts are unwanted, it may be possible to impregnate the outer trap surface with a mammalian-safe contact insecticide (such as a synthetic pyrethroid) to kill mirids that land on the trap. Alternatively, one could reduce the proportion of surface area of the trap by increasing the size and number of windows, with a possible benefit of rendering such traps more omni-directional.

One surprise finding was that applying sticker to the outside of pheromone traps increased significantly the numbers of $S$. singularis caught inside those traps. A possible explanation is that mirids may divert their flight path towards the trap entrance when they encounter the sticker odour, or dying mirids on the outside of the trap may release decay odours (or even an alarm pheromone), as suggested by Trematerra et al. (1996) for the flour beetle Tribolium castaneum (Herbst.), and so be diverted from landing on the outside of the trap into the catching arena.

McBrien and Millar (1999) suggest that some mirid species fly into pheromone-baited traps, while other species land initially in the vicinity of the pheromone source. They report that the latter behaviour is more common among other heteropteran families. Results from the present study (in which up to $80 \%$ of mirids were trapped on the outer surfaces of two trap types), suggest that direct flight into traps in response to a pheromone point source may be uncommon behaviour for $S$. singularis (and possibly for B. laticollis). Similarly, 
Storberget (2014) reported that 80-93\% of Lygus rugulipennis Poppius landed on the outer surface of pheromone traps in a strawberry crop.

In the trap height/placement experiments, trap catches of $S$. singularis showed a closer association with the cacao canopy than with absolute trap height. Although too few D. theobroma males were caught for parametric statistical analysis, all but five of the 22 caught in the three height experiments were trapped near the canopy. The increased catch of $S$. singularis by deploying traps close to canopy level, compared with deploying them at $1.8 \mathrm{~m}$, which is the previously recommended trap height (Sarfo et al., 2007), increased the numbers caught by an average 12-fold. Similarly, increased catches were seen at both Suhyen and Akwadum, despite the presence of four traps at each trap location at the former and a single trap at each trap point in the latter. The significant differences between captures at the various heights when multiple traps were presented suggests that there is little vertical displacement by $S$. singularis males when tracking to pheromone lures and little overlapping of the pheromone plumes, possibly because of long periods of calm air flow below the canopy (Murlis et al., 2000). However, our results suggest that the majority of mate-seeking males of both species orient flights near canopy height. Other non-cacao mirid species have been reported to orient flight near canopy level (McBrien et al., 1996; Ishimoto et al., 2006) and such behaviour is not uncommon for other nonmirid pests; for instance, the apple leaf roller Archips pomivora Meyrick (Bhardwajt and Chander, 1992).

The recommended trap height of $1.8 \mathrm{~m}$ is 1.58 SDs from the estimated mean optimal trap height of $5.6 \mathrm{~m}$, and as such, fewer than $25 \%$ of the total males in flight in mature cacao are likely to encounter the traps, i.e. those flying between 1.8 and $2.7 \mathrm{~m}$, although $1.8 \mathrm{~m}$ may be an appropriate elevation for traps in either immature cacao or clonal plantations. The estimated optimal trap elevation from our experiments is $c a 1 \mathrm{~m}$ below the top of the cacao canopy; however, as only a single trap height was investigated above the canopy, further trapping experiments are needed to establish whether $S$. singularis males fly above or below the cacao canopy.

The results suggest that the two experimental layouts, i.e. having several traps at a single position or single traps at several positions, produced similar distribution patterns for $S$. singularis and less convincingly for $D$. theobroma, owing to the low numbers of this species that were trapped. However, results from the experiment with single traps were less precise than from the experiments with multiple traps at one position, owing to the greater plotto-plot variation arising from the patchy spatial distribution of mirids (Gibbs et al., 1968; Bisseleua, et al., 2011).

\section{Conclusion}

Mirids are the most important insect pests of cacao in West Africa. The current dependence on blanket applications of synthetic insecticides for managing them is ecologically unsustainable. Exploitation of the known synthetic sex pheromones of the two dominant species provides opportunities for ecologically benign management. We found that pheromone traps made from products locally available in Ghana were as effective at capturing male mirids as the previous best trap fabricated from imported materials. Coating the exterior of traps with a sticker increased mirid captures 4.4fold in the best trap, and siting traps near canopy level also increased catches 12-fold compared to siting them at eye level. Further work is needed to establish whether this potential $\mathrm{ca} 50$-fold improvement to current pheromone trapping practice will provide an adequate base for developing ecologically benign, sustainable management of cacao mirids.

\section{Acknowledgements}

We are grateful to Cocoa Research (UK) for funding this work. We thank Dr Godfred Awudzi, Messrs Henry Ahiagaziga, Ebenezer Kwapong, Emmanuel Owusu, Colins Asumadu, Dickson Ampadu, Ebenezer Obeng-Mintah, Gordon Fiakegbe and Kofi Dadzie for technical assistance. This paper is published with the permission of the Executive Director, CRIG.

\section{References}

Anikwe J. C. and Makanjuola W. A. (2013) Effectiveness of some ecological pest management practices against the brown cocoa mirid, Sahlbergella singularis (Hemiptera: Miridae) in Nigeria. The Zoologist 11, 1-6.

Ayenor G. K., Van Huis A., Obeng-Ofori D., Padi B. and Röling N. G. (2007) Facilitating the use of alternative capsid control methods towards sustainable production of organic cocoa in Ghana. International Journal of Tropical Insect Science 27, 85-94.

Babin R., Sounigo O., Dibog L. and Nyassé S. (2004) Field tests for antixenosis and tolerance of cocoa towards mirids. INGENIC Newsletter 9, 45-50.

Bhardwajt S. P. and Chander R. (1992) Design and placement of synthetic sex attractant traps for monitoring apple leaf roller, Archips pomivora Meyrick (Lepidoptera: Tortricidae) in North Indian orchards. Tropical Pest Management 38, 61-64.

Bisseleua D. H. B., Yede and Vidal S. (2011) Dispersion models and sampling of cacao mirid bug Sahlbergella singularis (Hemiptera: Miridae) on Theobroma cacao 
in Southern Cameroon. Environmental Entomology 40, 111-119.

Collingwood C. A. (1977) African mirids, pp. 71-76. In Les Mirides du Cacaoyer (edited by E. M. Lavabre). Maisonneuve and Larose, Paris, France.

Collingwood C. A. and Marchart H. (1971) Chemical control of capsids and other insect pests in cocoa rehabilitation, pp. 89-99. In Proceedings of the 3rd International Cocoa Research Conference. 23-29 November, Accra, Ghana, Cocoa Research Institute, Tafo, Ghana.

Downham M. C. A., Cork A., Farman D., Hall D. R., Innoccenzi P., Phythian S., Padi B., Lowor S. and Sarfo J. E. (2002) Sex pheromone components of the cocoa mirids, Distantiella theobroma (Dist.) and Sahlbergella singularis Hagl. (Heteroptera: Miridae), p. 167. In Abstract Book, 19th Annual Meeting of the International Society of Chemical Ecology. 3-7 August 2002, Hamburg, Germany International Society of Chemical Ecology, Kentucky, USA. Available at: http: / / www.chemecol.org/programs/2002.pdf.

Entwistle P. F. (1972) Pests of Cocoa. Longman Group Ltd, London. 779 pp.

Entwistle P. F., Johnson C. G. and Dunn E. (1959) New pests of cocoa (Theobroma cacao L.) in Ghana following applications of insecticides. Nature 184, 2040-2041.

Gibbs D. G., Pickett A. D. and Leston D. (1968) Seasonal population changes in cocoa capsids (Heteroptera: Miridae) in Ghana. Bulletin of Entomological Research 58, 279-293.

Ishimoto M., Sato H., Muraoka Y., Aoki Y., Takita M., Noguchi T., Fukumoto T., Mochizuki F., Takahashi A. and Higuchi H. (2006) Monitoring adult rice leaf bug, Trigonotylus caelestialium (Kirkaldy) (Heteroptera: Miridae), with a synthetic sex pheromone trap in paddy fields. Japanese Journal of Applied Entomology and Zoology 50, 311-318.

Johnson C. G. (1962) Capsids: A review of current knowledge, pp. 316-331. In Agriculture and Land Use in Ghana (edited by J. B. Wills). Oxford University Press, London, New York.

Lavabre E. M., Decelle J. and Debord F. (1963) Etude de l'evolution regionale et saisonniere des populations des Mirides (Capsides) en Cote d'Ivoire. Café, Cacao, Thé 7, 267-289.

Mahob J. R., Babin R., ten Hoopen G. M., Dibog L., Yede, Hall D. R. and Bilong Bilong C. F. (2011) Field evaluation of synthetic sex pheromone traps for the cocoa mirid Sahlbergella singularis (Hemiptera: Miridae). Pest Management Science 67, 672-676.

Mahrizal L., Nalley L., Dixon B. L. and Popp J. (2012) Necessary price premiums to incentivize Ghanaian organic cocoa production: A phased, orchard management approach. HortScience 47, 1617-1624.

McBrien H. L. and Millar J. G. (1999) Phytophagous bugs, pp. 277-304. In Pheromones of Non-Lepidopteran Insects Associated with Agricultural Plants (edited by J. Hardie and A. K. Minks). CAB International, Wallingford, UK.
McBrien H. L., Judd G. J. R. and Borden J. H. (1996) Potential for pheromone-based mating disruption of the mullein bug, Campylomma verbasci (Meyer) (Heteroptera: Miridae). The Canadian Entomologist 128, 1057-1064.

Murlis J., Willis M.A. and Cardé R. T. (2000) Spatial and temporal structures of pheromone plumes in fields and forests. Physiological Entomology 25, 211-222.

Owusu-Manu E. (1994) Capsid thrust; mirid population. Annual Report of the Cocoa Research Institute of Ghana 1991/92, pp. 138-139.

Owusu-Manu E. (2002) New approach to mirid control on mature cocoa. Ghana Journal of Agricultural Science 35, 111-120.

Padi B., Oduor G. and Hall D. R. (2002) Development of mycoinsecticides and pheromones for cocoa mirids in Ghana. Final Technical Report. 1 October 1998-31 March 2002. 53 pp. Available at: https:/ / assets.publishing.service.gov.uk/media / 57a08d38e5274a31e000170c/R7249_FTR.pdf.

Perry J. N., Wall C. and Greenway A. R. (1980) Latin square designs in field experiments involving insect sex attractants. Ecological Entomology 5, 385-396.

Pimentel Gomes F. (1970) 281. Note: An extension of the method of joint analysis of experiments in complete randomised blocks. Biometrics 26, 332-336. doi: $10.2307 / 2529081$.

Sarfo J. E., Padi B., Hall D. H., Downham M. C. and Ackonor J. B. (2007) Effects of cocoa mirid pheromone trap positioning and density on trap catches, pp. 1635-1644. In Proceedings of the 15th International Cocoa Research Conference. 9-14 October 2006, San Jose, Costa Rica, Cocoa Producers Alliance, Lagos Nigeria.

SGER. (2013) State of the Ghana economy report, 2013. The Institute of Statistical Social \& Economic Research, University of Ghana, Legon (Accra), Ghana. Available at: https: / /www.ug.edu.gh/news / isser-launches-2013-state-ghanaian-economy-report (accessed 21 March 2016).

Stapley J. H. and Hammond P. S. (1959) Large scale trials with insecticides against capsids on cocoa in Ghana. Empire Journal of Experimental Agriculture 27, 343-353.

Storberget S. (2014) Catching the European tarnished plant bug Lygus rugulipennis using baited funnel traps. MSc thesis, Norwegian University of Life Sciences. 36 pp. Available at: http://hdl.handle.net/ 11250/225347 http://hdl.handle.net/11250/225348 (accessed 21 March, 2016).

Thomson D. R., Gut L. J. and Jenkins J.W. (1999) Pheromones for insect control, pp. 385-412. In Methods in Biotechnology, Volume 5: Biopesticides Use and Delivery (edited by F. R. Hall and J. J. Menn). Humana Press, Totowa, New Jersey, USA.

Trematerra P., Fontana F. and Mancini M. (1996) Effects of accumulated dead and alive insects in trap on the capture of Tribolium castaneum (Herbst). Anzeiger 
für Schädlingskunde, Pflanzenschutz, Umweltschutz 69, 3-9.

Witzgall P., Kirsch P. and Cork A. (2010) Sex pheromones and their impact on pest management. Journal of Chemical Ecology 36, 80-100.

Yasuda T. and Higuchi H. (2012) Sex pheromones of Stenotus rubrovittatus and Trigonotylus caelestialium, two mirid bugs causing pecky rice, and their application to insect monitoring in Japan. Psyche 2012, Article ID 435640.

Yonce C. E., Gentry C. R., Tumlinson J. H., Doolittle R. E. and Nielsen D. G. (1976) Lesser peachtree borer: Influence of trap height, substrates, concentration and trap design on capture of male moths with females and with a synthetic pheromone. Environmental Entomology 5, 417-420. doi: 10.1093/ee/5.3.417. 